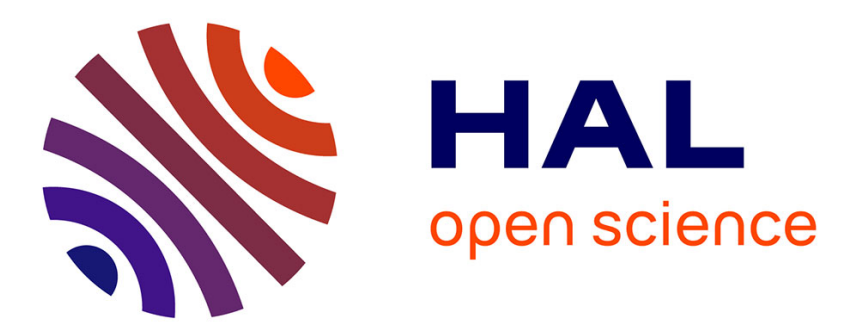

\title{
The Very Long-Term Outcome of Radiosurgery for Classical Trigeminal Neuralgia
}

Jean Régis, Constantin Tuleasca, Noémie Resseguier, Romain Carron, Anne Donnet, Shoji Yomo, Jean Gaudart, Marc Levivier

\section{To cite this version:}

Jean Régis, Constantin Tuleasca, Noémie Resseguier, Romain Carron, Anne Donnet, et al.. The Very Long-Term Outcome of Radiosurgery for Classical Trigeminal Neuralgia. Stereotactic and Functional Neurosurgery, 2016, 94 (1), pp.24-32. 10.1159/000443529 . hal-01368633

\section{HAL Id: hal-01368633 \\ https: / hal-amu.archives-ouvertes.fr/hal-01368633}

Submitted on 19 Sep 2016

HAL is a multi-disciplinary open access archive for the deposit and dissemination of scientific research documents, whether they are published or not. The documents may come from teaching and research institutions in France or abroad, or from public or private research centers.
L'archive ouverte pluridisciplinaire HAL, est destinée au dépôt et à la diffusion de documents scientifiques de niveau recherche, publiés ou non, émanant des établissements d'enseignement et de recherche français ou étrangers, des laboratoires publics ou privés.

\section{(ㅇ)(1) $\$$}

Distributed under a Creative Commons Attribution - NonCommercial - NoDerivatives 44.0 


\title{
Clinical Study
}

Stereotactic

and Functional

Neurosurgery
Stereotact Funct Neurosurg 2016;94:24-32

DOI: $10.1159 / 000443529$
Received: September 16, 2015

Accepted after revision: December 21, 2015

Published online: February 17, 2016

\section{The Very Long-Term Outcome of Radiosurgery for Classical Trigeminal Neuralgia}

\author{
Jean Régis ${ }^{a}$ Constantin Tuleasca $^{a}$ d-f Noémie Resseguier $^{\mathrm{b}}$ Romain Carron ${ }^{\mathrm{a}}$ \\ Anne Donnet $^{c}$ Shoji Yomo ${ }^{a}$ Jean Gaudart ${ }^{b}$ Marc Levivier ${ }^{e, f}$ \\ ${ }^{a}$ Functional and Stereotactic Neurosurgery Unit, INSERM U 751 (Université de la Méditerranée), b Department of \\ Public Health and Medical Information, UMR 912 (INSERM-IRD-Université de la Méditerranée), and 'Department of \\ Neurology, Clinical Neuroscience Federation, Centre Hospitalier Universitaire La Timone, Assistance Publique, \\ Hopitaux de Marseille, Marseille, France; ${ }^{\mathrm{d}}$ Signal Processing Laboratory (LTS 5), Swiss Federal Institute of \\ Technology (EPFL), Lausanne, and eNeurosurgery Service and Gamma Knife Center, Centre Hospitalier Universitaire \\ Vaudois, and ${ }^{\mathrm{f}}$ Faculty of Biology and Medicine, University of Lausanne, Lausanne, Switzerland
}

\section{Key Words}

Trigeminal neuralgia · Pain · Radiosurgery · Gamma Knife surgery

\section{Abstract \\ Background: Radiosurgery is one of the neurosurgical alter- natives for intractable trigeminal neuralgia (TN). Objective: Although acceptable short-/mid-term outcomes have been reported, long-term results have not been well documented. Methods: We report the long-term results in 130 patients who underwent radiosurgery for classical TN and were subse- quently monitored through at least 7 years (median $=9.9$, range $=7-14.5$ ) of follow-up. Results: The median age was 66.5 years. A total of 122 patients (93.8\%) became pain free (median delay $=15$ days) after the radiosurgery procedure (Barrow Neurological Institute, BNI class I-IIla). The probabil- ity of remaining pain free without medication at 3, 5, 7 and 10 years was 77.9, 73.8, 68 and 51.5\%, respectively. Fifty-six pa- tients (45.9\%) who were initially pain free experienced recur- rent pain (median delay $=73.1$ months). However, at 10 years, of the initial 130 patients, $67.7 \%$ were free of any recurrence}

\section{KARGER}

E-Mail karger@karger.com www.karger.com/sfn requiring new surgery (BNI class I-IIla). The new hypesthesia rate was $20.8 \%$ (median delay of onset $=12$ months), and only 1 patient $(0.8 \%)$ reported very bothersome hypesthesia. Conclusions: The long-term results were comparable to those from our general series (recently published), and the high probability of long-lasting pain relief and rarity of consequential complications of radiosurgery may suggest it as a firstand/or second-line treatment for classical, drug-resistant TN.

(c) 2016 S. Karger AG, Basel

\section{Introduction}

Trigeminal neuralgia (TN) is a rare disorder of the fifth cranial nerve and is considered one of the most excruciatingly painful conditions that may be encountered in clinical daily practice. The first-line therapy is pharmacological (carbamazepine) [1]. Any patients not responding to this medication or a short roster of other medications are

J.R. and C.T. contributed equally to this work. (c) 2016 S. Karger AG, Basel

1011-6125/16/0941-0024\$39.50/0
Constantin Tuleasca, MD

Neurosurgery Service and Gamma Knife Center

Centre Hospitalier Universitaire Vaudois, Rue du Bugnon 44-46, BH-08 $\mathrm{CH}-1011$ Lausanne (Switzerland)

E-Mail constantin.tuleasca@ gmail.com 
considered for surgery, including open microvascular decompression (MVD) [2] or operative percutaneous ablative procedures that deliberately generate a lesion on the trigeminal nerve in Meckel's cave using physical, chemical or thermal agents [3]. Radiosurgery [4-7], invented by the Swedish neurosurgeon Lars Leksell [4] at the beginning of the 1950s, targets the intracisternal trigeminal nerve [8] with high doses of ionizing radiation and represents another surgical procedure that is distinguished from the percutaneous ones by its minimally invasive nature [9]. Due to the former, it is becoming increasingly used for medically refractory TN. Its safety and efficacy have been commonly demonstrated in short- and intermediate-term follow-up studies [7], but only we and three other groups have reported long-term evidence of safety and efficacy $[6,10-12]$.

As radiosurgery has been sometimes criticized for not addressing very long-term outcomes in idiopathic $\mathrm{TN}$, we felt the urge to address this crucial issue in the present manuscript.

\section{Materials and Methods}

\section{Patient Population}

Our study was designed to be open, self-controlled, noncomparative and prospective. A case report form was created and prospectively used since the first patient was treated at Timone University Hospital, Marseille, France. Both a clinical examination and a magnetic resonance imaging (MRI) scan were done for all patients. The MRI was regarded as critical to exclude other pathologies that can induce $\mathrm{TN}$, such as benign or malignant intracranial tumors, multiple sclerosis, vascular malformations, etc. The data were retrospectively analyzed.

\section{Patients}

Since July 1992 and until November 2010, 737 patients presenting with intractable TN were prospectively selected and treated with radiosurgery. A total of 130 consecutive patients treated between May 1993 and September 2003, all evaluated according to our prospective protocol, were followed up for more than 7 years. Patients with TN secondary to multiple sclerosis [13] or megadolicho-basilar artery compression [14], or having had a second radiosurgery [15], reputed to have more variable responses, were excluded. The Ethics Committee of the Timone University Hospital (CPPRB 1) approved our study.

\section{Diagnostic Criteria Using the International Headache Society} Definition

All patients fulfilled the criteria of the International Headache Society [16]. Evaluation of the type of trigeminal pain was made according to the classification proposed by Eller et al. [17], comprising idiopathic TN1 and TN2. TN1 is described as typically sharp, shooting, electrical shock-like pain, with pain-free intervals between the attacks, that is present for more than $50 \%$ of the time;
TN2 is described as an aching, throbbing or burning pain present for more than $50 \%$ of the time and that is constant in nature (constant background pain being the most significant attribute). Only patients whose TN fulfilled the diagnostic criteria of TN1 were included in this report.

\section{Radiosurgical Technique}

After the application of the Leksell Model G stereotactic frame (Elekta Instruments AB, Stockholm, Sweden) under local anesthesia, all patients underwent MRI and computerized tomographic (CT) imaging for target definition. Two volumetric stereotactic 3D MRI sequences were used to identify the trigeminal nerve: millimetric noncontrast $\mathrm{T} 2$-weighted constructive interference steadystate pulse sequences and millimetric contrast-enhanced T1weighted images. Skull base CT scans routinely supplemented these neuroradiological investigations in order to correct any distortion errors in the MRI studies [8].

Between May 1993 and September 2003 Gamma Knife models $\mathrm{B}, \mathrm{C}$ and $4 \mathrm{C}$ (Elekta Instruments $\mathrm{AB}$ ) were successively used. A single 4-mm collimator helmet was used for all patients, and a retrogasserian stereotactic target was positioned in the anterior cisternal portion of the trigeminal nerve (fig. 1) at a median distance of $8 \mathrm{~mm}$ (range $=4.9-14)$ anterior to the emergence of the nerve [8]. This radiosurgical target location has been classically and constantly used in our center throughout the time since we have treated the first patients for TN.

The median maximum dose delivered was $85 \mathrm{~Gy}$ (range $=70$ 90 ). We initially prescribe a dose of $90 \mathrm{~Gy}$ to the $100 \%$ isodose. Beam channel blocking is used depending on the maximal dose received by $10 \mathrm{~mm}^{3}$ of the brainstem. If this dose is $>15 \mathrm{~Gy}$, we decrease the prescribed dose, and then if still necessary we start plugging, making it possible for us to avoid the so-called 'Flickinger effect' (increasing the mean dose to the nerve increases toxicity) [18]. All interventions were performed by the senior neurosurgeon (J.R.).

\section{Follow-Up Course}

Initial follow-up consisted of a neurological evaluation at regular intervals of 3, 6, 9 and 12 months and on a yearly basis thereafter. This included facial sensory testing, corneal reflex and jaw motility. All patients were seen in person for the proper evaluation of safety and efficacy, with a rigorous neurological examination, including the above-mentioned. For very long-term followup updates, telephone interview were considered acceptable for patients who were unable to visit us either because of distance or general health conditions. The patients and the referring doctor were instructed to continue the medication unchanged for at least 1 month and then to diminish the drug doses progressively in the case of pain freedom. Every clinical evaluation made by our medical team during the follow-up course was prospectively noted in the database so that we had continuous and prospectively collected up-to-date information. The 15 items of essential data for scientific literature reporting outcomes of the surgical treatment of TN, as considered by Zakrzewska et al. $[19,20]$, were followed.

\section{Explicit Definitions of Outcome Measures}

Outcome measures included time to initial pain relief, the onset and timing of any sensory disturbance, the recurrence of pain and recurrence without further surgery. Initial pain relief was classified 


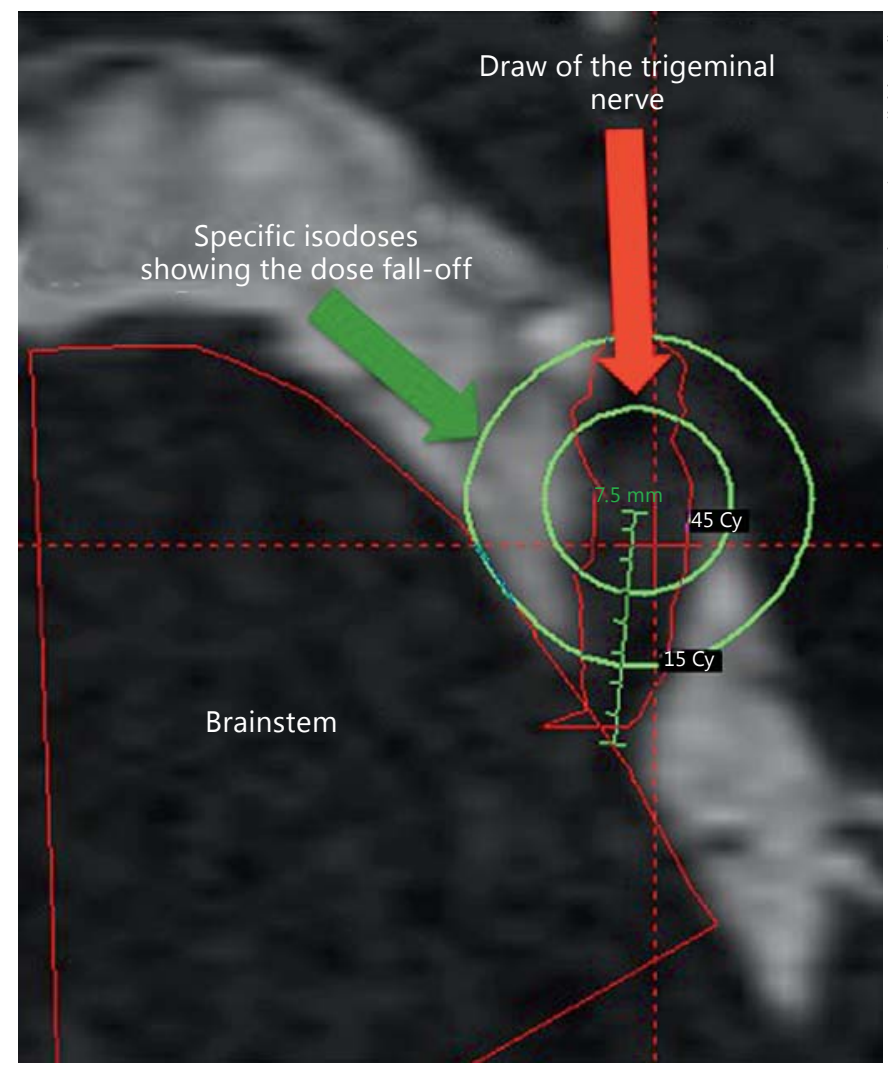

Fig. 1. Planning of a radiosurgical treatment by Gamma Knife for $\mathrm{TN}$. The targeting of the cisternal portion of the prepontine trigeminal nerve (red; color in online version only) on the side of the pain is based on a T2-weighted high-resolution MRI. Distortions of the MRI are evaluated (and corrected if necessary) based on a stereotactic CT performed the same day. The target is defined, in our group, at approximately $7.5 \mathrm{~mm}$ anterior to the emergence of the nerve. The selected dose at the maximum is typically 90 Gy but is decreased as low as $70 \mathrm{~Gy}$ in the case of high dosage potentially delivered to the brainstem due to the morphology of the cisternal anatomy.

according to the Barrow Neurological Institute (BNI) scale (table 1) [21]. The degree of hypesthesia was reported using the BNI facial hypesthesia scale [21] (table 1). The corneal reflex was assessed for all patients. Additionally, the appearance or absence of dysesthesias, paresthesias, anesthesia dolorosa, masseter muscle weakness, neurological complications outside the trigeminal nerve territory, systemic complications or death was noted.

A recurrence was defined as a change from class I to a lower outcome class. A minor recurrence was considered as one well tolerated by the patient (lower frequency and intensity of the pain) and not necessitating a new surgical therapy. A major recurrence was defined as one requiring an additional open, percutaneous or radiosurgical procedure.

\section{Patient Satisfaction}

Patient satisfaction was evaluated at the last follow-up. We used a semi-structured interview, conducted by the Gamma
Table 1. Pain outcome assessment according to BNI scale and BNI facial hypesthesia scale

\section{Description}

Grade $^{1}$, BNI pain intensity score

I No trigeminal pain, no medication

II Occasional pain, not requiring medication

IIIa No pain, continued medication

IIIb Persistent pain, controlled with medication

IV Some pain, not adequately controlled with medication

$\mathrm{V} \quad$ Severe pain/no pain relief

Grade, BNI facial numbness score

I No facial numbness

II Mild facial numbness, not bothersome

III Facial numbness, somewhat bothersome

IV Facial numbness, very bothersome

${ }^{1}$ Grade I-IIIa: significant pain relief; grade IIIb: adequate pain relief; grades IV and V are failures.

Knife team, during the follow-up visits. Responses in our semistructured questionnaire included: (1) No regret, I would undergo radiosurgery again with no hesitation; (2) No opinion, or (3) I regret having had radiosurgery (and would not have it done again).

\section{Statistical Analysis}

All statistical analyses were performed by two professional colleagues (the co-authors N.R. and J.G.) using the R software, version 2.12.0 (R Foundation for Statistical Computing, Vienna, Austria). For the evaluation of outcomes such as freedom from pain, hypesthesia and recurrence, the time-to-event was estimated using the Kaplan-Meier method. A bivariate analysis was then performed to identify predictive factors among the collected variables. For qualitative variables, Kaplan-Meier curves were used to graphically represent survival among the different groups, and were compared using the univariate log-rank test. For all variables, the effects were estimated and tested by fitting univariate Cox proportional hazards regression models. The proportionality of hazards was assessed graphically by log-cumulative hazard plots. For qualitative variables, the $\chi^{2}$ test was performed when valid; otherwise the Fisher exact test was used. The Mann-Whitney test was performed for quantitative variables, given the number of patients. All tests were two-sided and p values $<0.05$ were judged to be significant.

\section{Results}

\section{Details of Follow-Up Period}

The median follow-up period was 118.4 months (range $=84.2-174.4)$. 
Table 2. Clinical preoperative demographic data $(\mathrm{n}=130)$

\begin{tabular}{|c|c|}
\hline \multicolumn{2}{|l|}{ Sex } \\
\hline Male & $57(43.8)$ \\
\hline Female & $73(56.2)$ \\
\hline Age, years & $66.5(28.8-89)$ \\
\hline Duration of follow-up, months & $118.4(84.2-174.4)$ \\
\hline \multicolumn{2}{|l|}{ Side of pain } \\
\hline Right & $67(51.5)$ \\
\hline Left & $63(48.5)$ \\
\hline Bilateral & $4(3.1)$ \\
\hline \multicolumn{2}{|l|}{ Pain distribution } \\
\hline $\mathrm{V} 2$ & $38(29.2)$ \\
\hline V3 & $26(20)$ \\
\hline $\mathrm{V} 2$ and V3 & $25(19.2)$ \\
\hline $\mathrm{V} 1$ and V2 & $22(16.9)$ \\
\hline V1 & $10(7.7)$ \\
\hline $\mathrm{V} 1-\mathrm{V} 3$ & $9(6.9)$ \\
\hline \multicolumn{2}{|l|}{ Preoperative MRI vascular conflict (other } \\
\hline than megadolichobasilar compression) & $74(56.9)$ \\
\hline No prior surgery & $82(63.1)$ \\
\hline Prior surgery & $48(36.9)$ \\
\hline 1 & $23(17.7)$ \\
\hline 2 & $17(13.1)$ \\
\hline$\geq 3$ & $8(6.1)$ \\
\hline \multicolumn{2}{|l|}{ Type of prior surgery } \\
\hline Radiofrequency lesion & $26(20)$ \\
\hline Balloon microcompression & $22(16.9)$ \\
\hline MVD & $10(7.7)$ \\
\hline Glycerol rhizotomy & $3(2.3)$ \\
\hline Side effects from prior surgery & $32(24.6)$ \\
\hline \multicolumn{2}{|l|}{$\begin{array}{l}\text { Facial sensibility before Gamma Knife } \\
\text { radiosurgery }\end{array}$} \\
\hline Normal & $101(77.7)$ \\
\hline Slight hypesthesia & $26(20)$ \\
\hline Severe hypesthesia & $3(2.3)$ \\
\hline Anesthesia & $0(0)$ \\
\hline
\end{tabular}

Data are presented as n (\%) or median (range), as appropriate.

\section{Basic Demographic Data}

The preoperative clinical demographic data are shown in table 2. The median age was 66.5 years (range $=28.8-$ $89)$. In this series, 57 patients $(43.8 \%)$ were men and 73 (56.2\%) were women.

The pain was on the right side in 67 patients $(51.5 \%)$ and on the left side in 63 (48.5\%). Only 4 patients (3.1\%) had bilateral pain, but never simultaneously. Pain was predominantly distributed in the V2 territory of the trigeminal nerve (29.2\%), followed by V3 (20\%), V2 and V3 (19.2\%), V1 and V2 (16.9\%), V1 (7.7\%), and V1, V2 and V3 (6.9\%).

The median time between pain onset and the radiosurgery treatment was 72.2 months (range $=1-387$ ). Preop-

Radiosurgery for Classical Trigeminal Neuralgia erative MRI revealed the presence of a neurovascular conflict in 74 cases (56.9\%).

\section{Data Regarding Previous Treatments}

Gamma Knife radiosurgery was the first surgical procedure in 82 patients (63.1\%). Forty-eight (36.9\%) patients had prior surgical procedures and of these, 23 $(17.7 \%)$ had only 1 previous intervention, 17 (13.1\%) had 2 previous surgeries and $8(6.1 \%)$ had 3 or more previous surgeries. Previous surgeries consisted of radiofrequency lesioning in 26 patients (20\%), balloon microcompression in 22 patients (16.9\%), MVD in 10 patients (7.7\%) and glycerol rhizotomy in 3 patients (2.3\%). All patients had drug-resistant TN or major intolerance to all pharmacological therapies. Sixty-eight patients (52.3\%) reported substantial side effects of drug therapy at the time of radiosurgery.

\section{Data of Side Effects Related to Prior Surgical Interventions}

Before radiosurgery, 29 patients $(22.3 \%)$ had a sensory disturbance consequent to a previous surgical procedure and/or their TN, consisting of slight hypesthesia in 26 cases (20\%) and severe hypesthesia in $3(2.3 \%)$.

\section{Probability of Freedom from Pain after Radiosurgery}

A total of 122 patients (93.8\%) became pain free after the Gamma Knife radiosurgical procedure with or without medication (BNI classes I-IIIa, median delay to pain relief $=15$ days, range $=0-180$ ). The initial pain freedom rate at $0.5,1,2,3,4,5$ and 6 months was 54.6, 73.9, 86.2, $89.2,90,90.8$ and $92.3 \%$, respectively. The probability of becoming pain free after radiosurgery was dependent on the time since radiosurgery and reached a plateau at 6 months (fig. 2a). The duration of pain before Gamma Knife ( $p=0.73)$, the sex of the patient $(p=0.56)$ and the effect of a prior surgery ( $p=0.33$ for one, $p=0.55$ for two, $\mathrm{p}=0.09$ for three or more) were not statistically significant. Previous MVD ( $\mathrm{p}=0.01)$ was already advocated as a negative predictor for initial pain relief in one of our previous studies [28] and applies also to the current one.

\section{Sensory Dysfunction}

No patient developed an early complication after radiosurgery. Overall, 21 of 101 patients (20.8\%) without previous facial sensory symptoms developed new sensory dysfunction later, such as paresthesias or objective facial sensory loss, which occurred most frequently during the first 5 years after radiosurgery (table 3 ). The actuarial rate of developing new hypesthesia was $19.8 \%$ at 5 years, 


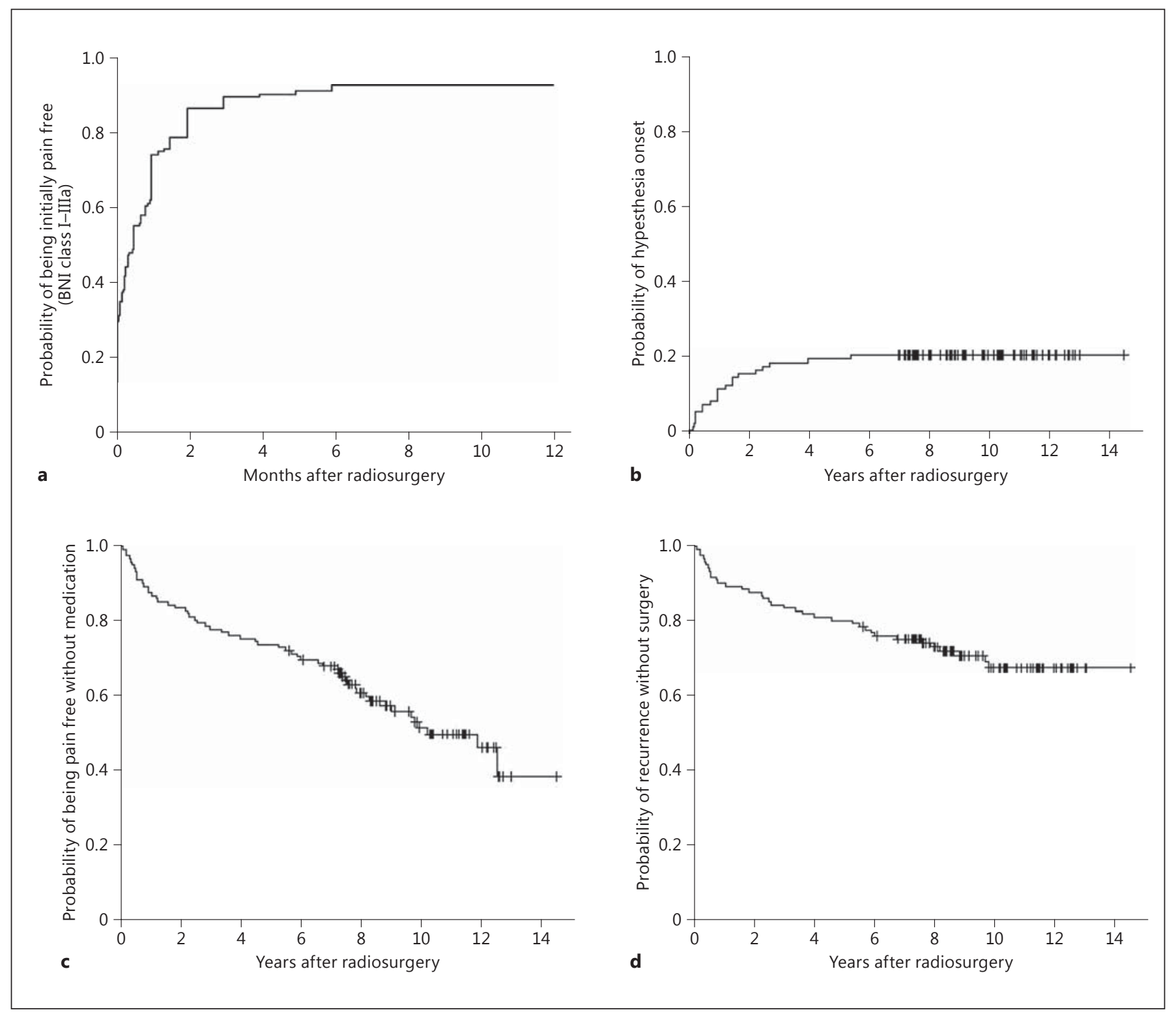

Fig. 2. Probability of being initially pain free and having new hypesthesia onset depending on time since radiosurgery. a The probability of becoming pain free reaches a plateau at 6 months (with a pain freedom rate of $92.3 \%$ ). Rates of freedom from pain as well as the number of patients at risk of the event, the number that achieve the event, the survival rate and the standard error, as well as the lower and upper $95 \% \mathrm{CI}$ were calculated. The initial pain-free rate at $0.5,1,2,3,4,5,6$ months was $54.6,73.9,86.2,89.2,90,90.8$ and $92.3 \%$, respectively. $\mathbf{b}$ The probability of new hypesthesia reached

a plateau at 5 years (with a hypesthesia rate of $20.8 \%$ ). c, d The probability of maintaining pain relief without medication (c) and the probability of maintaining pain relief without requiring new surgery (minor recurrence, d) depending on the time since pain cessation. The rate of pain freedom without medication (c) at 3, 5, 7,10 and 12 years was $77.9,73.8,68,51.5$ and $46.4 \%$, respectively. The rate of pain freedom without new surgical treatment (d) at 3, $5,7,10$ and 12 years was 83.6, 80.3, 75.4, 67.7 and $67.7 \%$, respectively.

reached $20.8 \%$ at 7 years, and remained stable until 14 years (fig. 2b). Among those experiencing hypesthesia, the median interval between radiosurgery and the onset of hypesthesia was 12 months (range $=0.5-65$ ). Accord-

ing to the BNI facial hypesthesia scale, facial numbness was mild in 19 patients (18.8\%), somewhat bothersome in 1 patient $(0.8 \%)$, and very bothersome in 1 patient $(0.8 \%)$. 
Table 3. Postoperative assessment and patient satisfaction survey: the opinion of the patients about the benefit provided by radiosurgery $(n=130)$

\begin{tabular}{|c|c|}
\hline Initially pain free & $122(93.8)$ \\
\hline Postradiosurgical sensory dysfunction & $21(16.1)$ \\
\hline Mild & $15(11.5)$ \\
\hline Severe & $6(4.6)$ \\
\hline \multicolumn{2}{|l|}{ BNI facial hypesthesia scale } \\
\hline No facial numbness & $109(83.8)$ \\
\hline Mild facial numbness & $19(18.8)$ \\
\hline Facial numbness, somewhat bothersome & $1(0.8)$ \\
\hline Facial numbness, very bothersome & $1(0.8)$ \\
\hline Recurrence of pain & $56 / 122(45.9)$ \\
\hline Time to pain recurrence, months & $73.1(0.9-150.1)$ \\
\hline Additional treatments after Gamma Knife radiosurgery & $42(32.3)$ \\
\hline 1 & $28(21.5)$ \\
\hline 2 & $10(7.7)$ \\
\hline$\geq 3$ & $4(3.1)$ \\
\hline Balloon microcompression & $22(16.9)$ \\
\hline Radiofrequency lesion & $11(8.5)$ \\
\hline MVD & $9(6.9)$ \\
\hline Cortical stimulation & $1(0.8)$ \\
\hline Gamma Knife radiosurgery & $8(6.1)$ \\
\hline \multicolumn{2}{|l|}{ Opinion of the patient } \\
\hline No regret, I would undergo radiosurgery again with no hesitation & $121(93.1)$ \\
\hline No opinion & $6(4.6)$ \\
\hline I regret having had radiosurgery (and would not have it done again) & $3(2.3)$ \\
\hline \multicolumn{2}{|c|}{$\begin{array}{l}\text { Data are presented as n (\%) or median (range), as appropriate. The vast majority (93.1\%) expressed a high } \\
\text { level of satisfaction, did not regret performing radiosurgery and would undergo it again. In contrast, } 3 \text { patients } \\
\text { were not satisfied with the result of radiosurgery and would not accept having the procedure nowadays. One of } \\
\text { these dissatisfied patients got no pain relief while experiencing nondisabling hypesthesia; } 1 \text { patient who had un- } \\
\text { dergone several operations before radiosurgery (1 MVD and } 2 \text { thermocoagulations) and who had facial hypes- } \\
\text { thesia before Gamma Knife radiosurgery experienced a good therapeutic effect from the radiosurgery, but had a } \\
\text { frank worsening of his preexisting hypesthesia; the third patient underwent a thermocoagulation before Gamma } \\
\text { Knife radiosurgery, and because he had only a transient benefit from radiosurgery he received MVD and a second } \\
\text { thermocoagulation and ultimately developed neuropathic pain. }\end{array}$} \\
\hline
\end{tabular}

The majority of the patients considered that their quality of life improved after radiosurgery and that the sensory dysfunction, when present, was a good trade-off for pain relief. Only 3 patients $(2.3 \%)$ reported that their quality of life was worse and that sensory dysfunction was not a good trade-off. No patient developed a trigeminal motor deficit or other cranial nerve deficits after radiosurgery.

\section{Probability of Pain Relief without Medication}

The probability of achieving and maintaining pain relief without medication at $0.5,1,2,3,5,7,10,12$ and 14 years was 93.4, 85.9, 78.6, 71.8, 64.9, 59.7, 45.3, 40.7 and $33.9 \%$, respectively (fig. 2c). The probability of remaining pain free was higher, with a shorter delay between TN pain onset and radiosurgery $[p=0.04$, hazard ratio
$(\mathrm{HR})=1,95 \%$ confidence interval $(\mathrm{CI})=0.99-1]$ but was not influenced by the development of postradiosurgery hypesthesia $(\mathrm{p}=0.88)$ or the existence of a neurovascular conflict on MRI ( $p=0.38)$, with the same applying to plugging $(\mathrm{p}=0.14)$. Furthermore, an earlier initial response predicted a better long-term benefit $(\mathrm{p}<0.05)$.

\section{Probability of Pain Relief Not Requiring New Surgery} (Minor Recurrence)

The probability of achieving and maintaining pain relief not requiring further surgery at 6 months and 1,2, 3, 5,7 and 10 years was $94.3,90.2,87.7,83.6,80.3,75.4$ and $67.7 \%$, respectively, and remained stable until 14 years (fig. 2d). Maintaining pain relief without further surgery was significantly associated with the presence of postradiosurgery hypesthesia $(\mathrm{p}=0.04, \mathrm{HR}=0.13,95 \% \mathrm{CI}=$ 
0.02-0.98). Conversely, recurrence with the need for further surgery was statistically associated with bilaterality of the preradiosurgery pain $(\mathrm{p}=0.03, \mathrm{HR}=3.59,95 \% \mathrm{CI}=$ $1.1-11.73)$ and pain within the V3 territory $(\mathrm{p}=0.05$, $\mathrm{HR}=2.92,95 \% \mathrm{CI}=0.99-8.62$ )

\section{Management of Recurrent Pain}

Fifty-six patients (45.9\%) who were initially pain free experienced at least one recurrence with a median delay of onset of 73.1 months (range $=0.9-150.1$ ). Fourteen patients had only minor recurrences, as their pain could be adequately managed with medication. Medically refractory ('major') pain recurred in 42 patients (32.3\%) who required further surgery. Twenty-eight patients $(66.7 \%)$ required only 1 further surgery, $10(23.8 \%)$ required 2 further surgeries and $4(9.5 \%)$ required 3 or more surgeries (table 3 ). In our center, the most common intervention after failed radiosurgery was balloon compression rhizotomy (22 patients, $52.4 \%$ ), followed by radiofrequency thermorhizotomy (11 patients, 26.2\%), MVD (9 patients, 21.4\%), repeated radiosurgery (8 patients, 19\%) and cortical stimulation (1 patient, $2.4 \%)$. In general, if a first-intention MVD treatment was proposed but declined by the patient, it was usually suggested a second time and frequently accepted by the patient in cases when radiosurgery was not efficacious.

\section{Discussion}

Physician and patient interest in radiosurgery as a first- and/or second-line therapy in medically refractory TN has consistently grown, especially after the cornerstone paper published by Kondziolka et al. [22], which fomented 'a revolution in functional neurosurgery' [7]. The mechanisms of action of radiosurgery for TN are not completely elucidated, but it seems to primarily affect myelin at the radiosurgery site [23]. Clinical evidence exists nowadays for factors that predict for a lower degree of radiosurgery efficacy, including multiple sclerosis [13], previous MVD [24], previous surgical treatment on the same side [8] or atypical TN.

The current literature includes few studies with longterm follow-up $[6,7,10,11]$. In chronological order, in 2009, Dhople et al. [10] reported a series of 102 patients with a median follow-up period of 5.6 years. Although they presented comparable rates to those published to date in terms of achieving freedom from pain (81\%), bothersome hypesthesia was as high as $6 \%$, and they re- ported rather disappointing durably positive results (only $22 \%$ ) at 7 years. In 2010, Kondziolka et al. [6] published a series from Pittsburgh, with a rather low rate of hypesthesia $(10.5 \%)$ and a 10 -year rate of $29 \%$ of patients who were pain free without medication. We recently reported our results [11] in a series of 497 patients with more than one-year follow-up (median $=43.8$ months, range $=28.1-$ 93.2). After a very good initial response (91.75\%), $45.3 \%$ of patients were still pain free without medication at 10 years. In that series, the hypesthesia rate was $21.1 \%$, with a plateau reached at 7 years, which remained stable for up to 14 years. Additionally, very bothersome hypesthesia was reported in only 3 patients $(0.6 \%)$.

To the best of our knowledge, the present study is the first to report very long-term follow-up with a large number of patients $(n=130)$. Initial pain relief was reported by $93.8 \%$ of patients, with a median delay of 15 days after radiosurgery. The new hypesthesia rate was low, at $20.8 \%$ (with a median delay of onset of 12 months after radiosurgery), with only 1 patient $(0.8 \%)$ reporting very bothersome hypesthesia. The probability of remaining pain free at 10 years was $51.5 \%$. An added value of our analysis is the reporting of the actuarial rate of patients free of any recurrence requiring new surgery: $67.7 \%$ at 10 years after radiosurgery.

As for the other surgical techniques, MVD, pioneered by Peter Jannetta, is presently considered the reference procedure, as it addresses the cause (e.g. the vascular loop compressing the nerve). It mainly consists of a small craniotomy to facilitate exposure and access to the nerve where it exits the brainstem. After identifying the offending vascular loop, this is separated by the nerve using a small Teflon pad. In the largest published series (Barker et al. [2]), with a median follow-up of 6.2 years, the initial rate of achieving freedom from pain was $98 \%$, with $82 \%$ being completely pain free. After 10 years, $70 \%$ still had an excellent response (pain relief without medication). Severe facial numbness was encountered in $1.8 \%$, and major complications included, in decreasing order, chemical meningitis (19\%), cerebrospinal fluid leak (1.7\%), ipsilateral hearing loss (1.3\%), extraocular muscle palsy (1.2\%) and facial palsy, etc. (1\%), with a very low, but nonzero postoperative death rate $(0.2 \%)$.

Percutaneous techniques are ablative, as they act by causing a destruction of the nerve fibers, either by thermal energy (radiofrequency rhizotomy) or by chemical (glycerol rhizotomy) or mechanical damage (balloon microcompression). In this context, they commonly cause facial numbness to varying degrees, as a condition for complete and prolonged efficacy. They are generally
Régis/Tuleasca/Resseguier/Carron/ Donnet/Yomo/Gaudart/Levivier 
straightforward and safe, and are performed in the operating room. The initial pain relief rates range between 90 and $97.6 \%$ for all these techniques, and at 3 years the pain relief rate falls to between 53 and $69 \%$, with severe numbness occurring in up to $20-23 \%$ of patients. These procedures are notable for high recurrences rates (as high as $26 \%$ at a very short mean time of 18 months) [3, 25-27]. Additionally, other procedure-associated complications include exposure keratitis ( $0-2 \%)$, anesthesia dolorosa $(0-2.5 \%)$, troublesome dysesthesias (4-10\%) and masticatory weakness $(0-12 \%)[3,25-27]$.

The most commonly performed functional neurosurgery procedure is for $\mathrm{TN}$, representing up to $90 \%$ of all such procedures, including those in our center. There have been technical refinements over time which aimed at improving the safety and efficacy. Hypesthesia is not mandatory for achieving and maintaining pain relief, pointing out the fact that radiosurgery is not an ablative procedure. Patient satisfaction in our series was good, since $93.1 \%$ expressed a high level of satisfaction. The present study gives an overview of radiosurgical results on the basis of the very long-term follow-up. With an importantly large cohort of patients and an extended followup period, it provides a worthy comparison to our global series [11], providing evidence of high safety and efficacy of radiosurgery in idiopathic $\mathrm{TN}$.

\section{Acknowledgment}

This study received funding from Timone University Hospital, Marseille, France.

\section{Disclosure Statement}

The authors declare no conflicts of interest.

\section{References}

1 Cruccu G, Truini A: Refractory trigeminal neuralgia. Non-surgical treatment options. CNS Drugs 2013;27:91-96.

2 Barker FG 2nd, Jannetta PJ, Bissonette DJ, Larkins MV, Jho HD: The long-term outcome of microvascular decompression for trigeminal neuralgia. N Engl J Med 1996;334:1077-1083.

3 Cheng JS, Lim DA, Chang EF, Barbaro NM: A review of percutaneous treatments for trigeminal neuralgia. Neurosurgery 2013, Epub ahead of print.

4 Leksell L: The stereotaxic method and radiosurgery of the brain. Acta Chir Scand 1951; 102:316-319.

5 Leksell L: Stereotaxic radiosurgery in trigeminal neuralgia. Acta Chir Scand 1971;137:311314.

6 Kondziolka D, Zorro O, Lobato-Polo J, Kano H, Flannery TJ, Flickinger JC, Lunsford LD: Gamma Knife stereotactic radiosurgery for idiopathic trigeminal neuralgia. J Neurosurg 2010;112:758-765.

7 Regis J, Tuleasca C: Fifteen years of Gamma Knife surgery for trigeminal neuralgia in the Journal of Neurosurgery: history of a revolution in functional neurosurgery. J Neurosurg 2011;115(suppl):2-7.

8 Regis J, Metellus P, Hayashi M, Roussel P, Donnet A, Bille-Turc F: Prospective controlled trial of Gamma Knife surgery for essential trigeminal neuralgia. J Neurosurg 2006;104:913-924.

9 Cruccu G, Gronseth G, Alksne J, Argoff C, Brainin M, Burchiel K, Nurmikko T, Zakrzewska JM; American Academy of Neurology Society; European Federation of Neurological
Society: AAN-EFNS guidelines on trigeminal neuralgia management. Eur J Neurol 2008; 15 : 1013-1028.

10 Dhople AA, Adams JR, Maggio WW, Naqvi SA, Regine WF, Kwok Y: Long-term outcomes of Gamma Knife radiosurgery for classic trigeminal neuralgia: implications of treatment and critical review of the literature. Clinical article. J Neurosurg 2009;111:351358.

11 Regis J, Tuleasca C, Resseguier N, Carron R, Donnet A, Gaudart J, Levivier M: Long-term safety and efficacy of Gamma Knife surgery in classical trigeminal neuralgia: a 497-patient historical cohort study. J Neurosurg 2015, Epub ahead of print.

12 Young B, Shivazad A, Kryscio RJ, St Clair W, Bush HM: Long-term outcome of high-dose Gamma Knife surgery in treatment of trigeminal neuralgia. J Neurosurg 2013;119:11661175 .

13 Tuleasca C, Carron R, Resseguier N, Donnet A, Roussel P, Gaudart J, Levivier M, Regis J: Multiple sclerosis-related trigeminal neuralgia: a prospective series of 43 patients treated with Gamma Knife surgery with more than one year of follow-up. Stereotact Funct Neurosurg 2014;92:203-210.

14 Tuleasca C, Carron R, Resseguier N, Donnet A, Roussel P, Gaudart J, Levivier M, Regis J: Trigeminal neuralgia related to megadolichobasilar artery compression: a prospective series of twenty-nine patients treated with Gamma Knife surgery, with more than one year of follow-up. Stereotact Funct Neurosurg 2014;92:170-177.
15 Tuleasca C, Carron R, Resseguier N, Donnet A, Roussel P, Gaudart J, Levivier M, Regis J: Repeat Gamma Knife surgery for recurrent trigeminal neuralgia: long-term outcomes and systematic review. J Neurosurg 2014; 121(suppl 2):210-221.

16 Society HcsotIH; Headache Classification Subcommittee of the international Headache Society: The International Classification of Headache Disorders. Oxford, Blackwell, 2004.

17 Eller JL, Raslan AM, Burchiel KJ: Trigeminal neuralgia: definition and classification. Neurosurg Focus 2005; 18:E3.

18 Flickinger JC, Pollock BE, Kondziolka D, Phuong LK, Foote RL, Stafford SL, Lunsford LD: Does increased nerve length within the treatment volume improve trigeminal neuralgia radiosurgery? A prospective double-blind, randomized study. Int J Radiat Oncol Biol Phys 2001;51:449-454.

19 Zakrzewska JM, Thomas DG: Patient's assessment of outcome after three surgical procedures for the management of trigeminal neuralgia. Acta Neurochir (Wien) 1993;122:225230 .

20 Zakrzewska JM, Lopez BC: Quality of reporting in evaluations of surgical treatment of trigeminal neuralgia: recommendations for future reports. Neurosurgery 2003;53:110-120; discussion 120-122.

21 Rogers CL, Shetter AG, Fiedler JA, Smith KA, Han PP, Speiser BL: Gamma Knife radiosurgery for trigeminal neuralgia: the initial experience of the Barrow Neurological Institute. Int J Radiat Oncol Biol Phys 2000;47:10131019. 
22 Kondziolka D, Lunsford LD, Flickinger JC, Young RF, Vermeulen S, Duma CM, Jacques DB, Rand RW, Regis J, Peragut JC, Manera L, Epstein MH, Lindquist C: Stereotactic radiosurgery for trigeminal neuralgia: a multiinstitutional study using the gamma unit. J Neurosurg 1996;84:940-945.

23 Love S, Coakham HB: Trigeminal neuralgia: pathology and pathogenesis. Brain 2001;124: 2347-2360.

24 Tuleasca C, Carron R, Resseguier N, Donnet A, Roussel P, Gaudart J, Levivier MA, Régis J: Decreased probability of initial pain cessation in classical trigeminal neuralgia treated with gamma knife surgery in case of previous mi- crovascular decompression: a prospective series of 45 patients with more than one year of follow-up. Neurosurgery 2015;77:87-94; discussion 94-95.

25 Brown JA, McDaniel MD, Weaver MT: Percutaneous trigeminal nerve compression for treatment of trigeminal neuralgia: results in 50 patients. Neurosurgery 1993;32:570573.

26 Kanpolat Y, Savas A, Bekar A, Berk C: Percutaneous controlled radiofrequency trigeminal rhizotomy for the treatment of idiopathic trigeminal neuralgia: 25-year experience with 1,600 patients. Neurosurgery 2001;48:524532; discussion 532-534.
27 North RB, Kidd DH, Piantadosi S, Carson BS: Percutaneous retrogasserian glycerol rhizotomy. Predictors of success and failure in treatment of trigeminal neuralgia. J Neurosurg 1990;72:851-856.

28 Tuleasca C, Carron R, Resseguier N, Donnet A, Roussel P, Gaudart J, Levivier M, Régis J: Decreased Probability of Initial Pain Cessation in Classic Trigeminal Neuralgia Treated With Gamma Knife Surgery in Case of Previous Microvascular Decompression: A Prospective Series of 45 Patients With $>1$ Year of Follow-up. Neurosurgery 2015;77:8794(discussion 94-95. doi: 10.1227/ NEU.0000000000000739). 